\title{
Dimensioning of nursing staff in outpatient chemotherapy: application of the Workload Indicators of Staffing Need*
}

\author{
Dimensionamento de profissionais de enfermagem em quimioterapia \\ ambulatorial: aplicação do método Workload Indicators of Staffing Need \\ Dimensionamiento de profesionales enfermeros en quimioterapia ambulatoria: \\ aplicación del método Workload Indicators of Staffing Need
}

How to cite this article:

Santos DV, Gaidzinski RR. Dimensioning of nursing staff in outpatient chemotherapy: application of the Workload Indicators of Staffing Need. Rev Esc Enferm USP. 2019;53:e03456. DOI: http://dx.doi.org/10.1590/S1980-220X2018003803456

\section{Daniela Vivas dos Santos ${ }^{1}$ \\ Raquel Rapone Gaidzinski ${ }^{1}$}

* Extracted from the thesis: "Dimensionamento de profissionais de enfermagem para assistência oncológica ambulatorial: aplicação do método WISN', Universidade de São Paulo, 2018.

${ }^{1}$ Universidade de São Paulo, Escola de Enfermagem, São Paulo, SP, Brazil.

\begin{abstract}
Objective: To apply the method developed by the World Health Organization, called Workload Indicators of Staffing Need for dimensioning the nursing staff for the care of cancer patients in a Chemotherapy outpatient clinic. Method: This is a quantitative, observational, documentary field study with an intentional sample. Prospective data were collected through the work sampling method. Results: Seventeen nurses and 12 nursing technicians participated in the study. A total of 3,727 observations were performed and were obtained the mean times and the relative working time of 23 nurses interventions and 18 nursing technicians' interventions. The interventions corresponded to $88.5 \%$ of the relative working time of nurses and $83.9 \%$ of nursing technicians. Personal activities accounted for $8.2 \%$ of the relative working time of nurses and $7.9 \%$ of nursing technicians. The reliability test resulted in $86.3 \%$ concordance. Conclusion: The similarity between the staff required according to the method studied and the current staff showed that the Workload Indicators of Staffing Need has great potential and applicability for dimensioning nursing professionals safely.
\end{abstract}

DESCRIPTORS

Oncology Nursing; Nursing Staff; Workload; Ambulatory Care. 


\section{INTRODUCTION}

The antineoplastic chemotherapy treatment is complex and requires a multidisciplinary team. The nursing staff stands out among all professional categories involved because of its presence in most interventions ${ }^{(1)}$.

One of the challenging situations in the oncological context is that patient care happens predominantly in an outpatient setting. This requires the application of education, monitoring and safety actions (among others) to a great demand of patients during the short period they remain in the institution ${ }^{(2-3)}$.

The specific demand of outpatient chemotherapy services requires the application of validated methods for preparing the professional staff.

The issue of dimensioning of nursing personnel has been the focus of attention of nurses and service administrators, because it directly interferes in the effectiveness, quality and cost of health care ${ }^{(4)}$.

Regarding the national legislation, the Federal Nursing Council (Portuguese acronym: Cofen), through Resolution $543 / 2017^{(5)}$, proposed a calculation for sizing the nursing staff, including for outpatient clinics. To this end, were suggested functional sites, the experience-based unit and intuitive judgment of the Technical Responsible by considering the activities developed, the operational area and the work shift.

In the last decades, several methodologies have been proposed for dimensioning the nursing staff, among which the Workload Indicators of Staffing Need (WISN) stands out. It was developed in 1998 and revised in 2008 by the World Health Organization. This method allows planning for all categories of health workers, provides results such as the difference between the current and the calculated number, and subsidizes the best way to distribute professionals in the units of the institution ${ }^{(6)}$. In the WISN, health services workloads are used to define staffing needs by surveying the interventions developed and considering the complexity of care $\operatorname{provided}^{(7)}$.

The WISN method uses annual services statistics, i.e., is based on routinely collected data that impact on the healthcare professionals' workload. The records must be complete, available and of good quality, since data required refer to the previous year of each component of the workload of each unit ${ }^{(6)}$.

In the last ten years, were found six studies related to the subject in outpatient clinics of antineoplastic chemotherapy (CT), of which five measured the nursing workload in a CT outpatient clinic $^{(8-13)}$.

These studies ${ }^{(8-13)}$ contributed to the knowledge of nursing interventions in patient care in chemotherapy treatment, indicated the mean time of care per patient and the workload percentage distribution of $80 \%$ for nurses and $20 \%$ for nursing technicians ${ }^{(8)}$.

However, in the literature, studies applying the WISN method in the CT outpatient clinic were not found. Therefore, the performance of this study is justified by its novelty.
The use of this method is recent in Brazil, and it has been considered the most suitable for outpatient clinic settings. Cofen Resolution number 543/2017, Annex II, indicates the WISN as a possibility for the nursing staff dimensioning in primary care ${ }^{(5,14-16)}$.

Therefore, the aim of this study was to apply the WISN method for dimensioning the nursing staff for the care of cancer patients in a CT outpatient clinic.

\section{METHOD}

\section{TYPE OF STUDY}

This is a quantitative observational, documentary, field study with an intentional sample ${ }^{(10)}$.

\section{SCENARIO}

The setting of this study was a CT outpatient clinic of a public teaching institution of tertiary care specialized in adult oncology located in the city of São Paulo. This institution is an oncology reference center and has several quality service accreditations, including certification by the Joint Commission International in 2014 and 2017, thus it is considered a service with good practice.

The dimensioning of nursing staff for serving 230 patients/day included 29 nurses and 28 nursing technicians. Of these, 24 nurses and 26 nursing technicians were actively working.

As this study aimed to reflect the work dynamics of the nursing staff, all nurses and nursing technicians actively working in the sector were invited to participate.

The application and evaluation of the WISN sizing method in CT outpatient clinics were conducted in the following steps:

\section{Development OF THE DATA COLleCtion INSTRUMENT}

The instrument for collecting data related to interventions/activities that were part of the workload of nursing professionals was constructed based on the CT outpatient clinic records, which were later related to the Nursing Interventions Classification (NIC) ${ }^{(3)}$ and to instruments proposed in two studies $^{(8-9)}$ that also used the NIC classification ${ }^{(3)}$.

Based on these references, the instrument was validated during a workshop by judges with at least five years of experience in oncology. It included 35 nursing interventions and three activities (personal, standby and movement).

The group of judges was composed of 15 professionals with the following positions: nursing manager, nursing coordinator, nurse or nursing technician. Judges were invited to participate in the panel by personal contact scheduled previously. In the professionals' workplace, the researcher presented an invitation letter and explained the objectives of the study, about their participation, the time spent in the activity, as well as the date, place and time of the workshop. After the clarification of doubts and acceptance of the invitation letter, was sent by e-mail the proposal of an instrument with the list of interventions of the data collection instrument of this study that would be validated in the workshop. 
The workshop took place in a single four-hour face-toface meeting. Each intervention proposed in the instrument was read by the researchers and evaluated by the judges regarding representativeness and relevance of the interventions/activities developed in the sector according to the NIC definition.

In addition, was found the need to include or exclude interventions/activities. The validation of the inclusion or exclusion of each intervention happened according to the assessment of most judges.

After the validation of interventions considered as components of the workload, they were classified according to the WISN in: health service (interventions performed by all members of a staff category and recorded regularly), support (interventions performed by all members of a category and normally not recorded), and additional (interventions performed by some members of a staff category and whose statistics are not regularly recorded $)^{(6)}$.

\section{IDENTIFICATION OF MEAN TIME AND RELATIVE WORKING TIME OF WORKLIOAD COMPONENTS}

In order to identify the mean time and the relative working time when performing each intervention/activity, was used the work sampling method with a five-minute interval. Work sampling consists of intermittent random and instantaneous observations of work interventions/activities by independent observers that accurately record the type of activity, but not the time spent with it. The technique is based on the laws of probability, which indicate that the observation taken at repeated random moments will have the same distribution ${ }^{(16)}$.

The observation of nursing professionals during the work day at the CT outpatient clinic was performed by two field observers, who were newly trained nurses at the Nursing Oncology Improvement Course held at the Institution itself. Each observer followed an average of six nursing professionals per day.

The two field observers participated in the workshop as listeners for validation of the data collection instrument. They received theoretical and practical training of 20 hours.

During the data collection, the reliability test of the record of interventions made by nursing professionals was performed daily and concomitantly by one of the researchers (gold standard) with each field observer. Researchers were available from a distance if observers had any questions.

The calculation of $\mathrm{N}$ sample size required to statistically determine the quantitative values of variables interfering in the workload of nurses and nursing technicians of the CT outpatient clinic was based on the criteria detailed below.

In the study, data were collected randomly, because the sequence of nursing interventions/activities performed depended on patients' needs and did not suffer interference from the adopted research technique. Therefore, a conventional statistical analysis was possible; 95\% confidence interval $(\boldsymbol{a}=0.05)$; error of $5 \%$ between the mean value sampled and the mean value of the population, i.e., $\mathrm{d}=0.05$; mean value of time of interventions/activities $\overline{\boldsymbol{t}}_{\boldsymbol{i}}$ of nursing equal to 7 minutes obtained based on preliminary observation performed at the CT outpatient clinic; interval between samples of $\boldsymbol{\tau}=5$ minutes, which allows to detect the interventions/activities with mean time equal to or greater than $\boldsymbol{\tau}$ with error less than $20 \%{ }^{(17)}$; the sample size value $\mathrm{N}=1,000$ samples was obtained by extrapolating the number of categories (interventions) $j>15$ for the multinomial distribution.

\section{ANALYSIS AND PROCESSING OF DATA}

The collected data were transferred to spreadsheets and the following calculations were performed: related to absolute and relative frequency of interventions/activities, of the total time taken by the intervention/activity and its relative value, the mean time of each intervention/activity, of the standard deviation of data, and values of upper and lower limits of the $95 \%$ confidence interval.

The number of intervals occurring while performing the same intervention/activity was counted and grouped into classes of consecutive samples.

During the application of the work sampling method, the field observer found the nursing professional in activities that could not be attributed to a specific intervention, as when the professional was moving, in standby or in a personal activity. When this happened, the field observer recorded these occurrences as independent activities named: Movement; Standby; and Personal.

Following the proposed method, for calculation of mean times and the proportion of nursing working time, the time spent in these independent activities was proportionally distributed among the nursing interventions.

Standby and movement times were distributed among the interventions that predict these situations. Time in personal activities was distributed among all interventions.

The mean time of relative working time was obtained by the relation between the mean working time with distribution of activities among each intervention and the sum of working times with the distribution of the other observed interventions. The percentage value of the mean of relative working time was obtained multiplying by 100 .

The mean time of each intervention was calculated by the mean for grouped data.

\section{ApplicATION OF THE WISN}

Dimensioning of the nursing staff $Q_{\text {staff }}$ of the CT outpatient clinic was calculated by applying the sequential operations of the WISN method for each professional category $\boldsymbol{k}$ of this staff:

$$
Q_{\text {staff }}=Q_{\text {nurse }}+Q_{\text {technician }}
$$

The WISN defines the following equation for the calculation of personnel quantity $\boldsymbol{Q}_{k}$ for each professional category $k$ :

$$
Q_{k}=\left(A_{k} \times B_{k}\right)+C_{k}
$$

$A_{k}=$ required number of professionals in category $k$ to perform the Recorded Interventions $\left(\boldsymbol{i}_{r}\right)$; 
$B_{k}=$ allowance factor of professional category $k$ to perform Support Interventions;

$C_{k}=$ allowance factor of professional category $k$ to perform Additional Interventions.

The number of $\mathrm{Ak}$ professionals in category $\mathrm{k}$ required for performing all interventions that had the annual production $\mathrm{P}$ was systematically recorded by the institution. It was obtained by the sum of required professionals $\mathrm{q}_{\mathrm{k}}\left(\mathrm{i}_{\mathrm{r}}\right)$ calculated for each type of available intervention recorded $\mathrm{i}_{\mathrm{r}}$ :

$$
A_{k}=\sum_{i_{r}=1}^{n} q_{k}\left(i_{r}\right)
$$

The number of professionals required to perform each of the recorded interventions was calculated by the following equation:

$$
q_{k}\left(i_{r}\right)=\frac{P_{k}\left(i_{r}\right) \times \overline{\delta_{k}\left(i_{r}\right)}}{T T D_{k}}
$$

Where:

$\mathrm{P}_{\mathrm{k}}\left(\mathrm{i}_{\mathrm{r}}\right)=$ annual production of the recorded intervention ir performed by professionals of category $\mathrm{k}$ obtained by records of the institution in a given period;

$\overline{\delta_{k}(l)}=$ standard mean time for performing intervention $i r$ by professionals of category $k$ obtained by work sampling and by the estimation of sector;

$A W T_{k}=$ nursing professionals' available working time obtained by the work data of the institution by sector and by each professional category $\mathrm{k}$;

Available Working Time (AWT) is a nursing professional's available time in one year to perform his/her work taking into account expected and unforeseen absences ${ }^{(6)}$.

The reference unit can be days or hours. The equation shows the calculation:

$$
A W T_{k}=\left[T P_{k}-\left(T H_{k}+T V_{k}+T S_{k}+T L_{k}\right)\right] \times h_{k}
$$

Where:

$A W T_{k}=$ available working time in the year by professional in category $\mathrm{k}$ under study;

$T P_{k}=$ number of possible working days in one year obtained by multiplying the number of weeks in one year ( 52 weeks) by the number of days worked in one week by professionals in the professional category k under study;

$T H_{k}=$ number of absence days in the year due to holidays (national, state, municipal and institutional) by professional of category k under study;

$T V_{k}=$ average number of absence days per professional due to vacations in one year;

$T S_{k}=$ average number of absence days per professional in category $k$ due to sick leave in one year;

$T L=$ average number of absence days per professional in category $k$ due to other reasons (marriage, bereavement, maternity and training) in one year;

$h_{k}=$ number of hours worked by professional in category $\mathrm{k}$ in one day (working day).

Data related to $A W T_{k}$ were extracted from work data records systematically collected by the General Directorate of Assistance from May 1, 2015 to April 30, 2016.
The contribution factor $B_{k}$ of professionals in category $k$ in the performance of support interventions $i_{s}$ was obtained by applying the equation:

$$
B_{k}=\frac{1}{1-\frac{S_{k} \%}{100}}
$$

Where $S_{k} \%$ is the sum of the percentage of participation (standard relative working time) of category $k$ in the performance of interventions/activities of support obtained by the equation:

$$
S_{k} \%=100 . \sum_{i_{s}=1}^{n} \overline{T O R_{k}}\left(i_{s}\right)
$$

Where:

$\overline{\operatorname{TOR}_{k}}\left(i_{r}\right)=$ mean time of relative working time with each support intervention $i_{s}$ obtained by the equation of the work sampling method.

The individual allowance factor $C_{k}$ was only calculated for some nurses, because, according to data collected in the study, the technicians did not perform additional services. This factor was calculated by applying the equation:

$$
C_{n u r}=\frac{\sum_{n u r=1}^{n} C t a_{n u r}}{T T D_{n u r}}
$$

Where:

$C t_{\text {nur }}=$ annual workload of each nurse who performed additional interventions;

$A W T_{\text {nur }}=$ available working time in the professional category of nurses.

After identification of the AWT, the mean time of interventions recorded, the percentage of working time of support interventions, and hours invested in additional interventions, was possible to dimension the categories of nurses and nursing technicians.

For an easier application of the WISN method, was developed an electronic spreadsheet adapted from the calculation spreadsheet for dimensioning the nursing staff in primary health care, as in Cofen Resolution number $543 / 2017^{(5)}$.

After dimensioning the staff by applying the WISN, it was compared with the current staff. The differences found were used to classify the workload pressure on the sector, defined as: normal, when the ratio was close to 1 ; high, when the ratio was less than or equal to 0.7 ; low, when the ratio was $0.8-0.9$; and none when the ratio found was greater than 1 .

\section{ETHICAL ASPECTS}

This study was performed according to the guidelines of Resolution 466/12 of the National Health Council ${ }^{(18)}$, and was approved by the Research Ethics Committees of the School of Nursing (number 1.833.130) and the Faculty of Medicine (number 1.856.509) from the Universidade de São Paulo. 
After clarifying the objectives of the study, the right to anonymity and about voluntary participation, the consent of participants was formalized by signing the Informed Consent form.

\section{RESULTS}

Seventeen nurses participated in the study, and the profile was characterized by females (93.7\%), mean age of 35 years, five years of working time in the institution, of which four years in the CT sector, weekly workload of 40 hours and complete specialization course (86.66\%). Twelve nursing technicians participated, who were predominantly female (91.6\%), mean age of 35 years, five years of working time in the institution, of which four years in the CT sector with a weekly workload of 40 hours, $81.8 \%$ with complete technical level, and $18.2 \%$ with undergraduate courses.

Application of the work sampling method included eight days of data collection and resulted in 3,727 observations, of which 2,034 (54.6\%) of nurses and 1,693 (45.4\%) of nursing technicians.

The reliability test was performed in 666 (17.9\%) simultaneous observations by one of the researchers and field observers and resulted in $86.3 \%$ concordance.

Data from the work sampling method related to the performance of CT outpatient nurses showed the relative working time was distributed as follows: nursing interventions of $88.5 \%$, personal activity of $8.2 \%$, standby time of $3.1 \%$ and movement of $0.1 \%$. Regarding nursing technicians, the relative working time of interventions represented 83.9\%, while personal activity corresponded to $7.9 \%$, standby time was $7.5 \%$ and movement was $0.7 \%$.

After the proportional distribution of times related to personal activities, standby and movement among the nursing interventions (as described in the method), were obtained the mean time parameters of each intervention (Table 1).

Table 1 - Distribution of interventions performed by the CT outpatient clinic nursing staff with distributed values - São Paulo, SP, Brazil, 2017.

\begin{tabular}{|c|c|c|c|c|c|c|c|}
\hline \multirow[b]{2}{*}{ NIC code } & \multirow[b]{2}{*}{ Name of interventions } & \multicolumn{3}{|c|}{ Nurse } & \multicolumn{3}{|c|}{ Nursing Technician } \\
\hline & & $\begin{array}{c}\mathrm{N} . \\
\text { Interventions }\end{array}$ & $\begin{array}{c}\text { Relative } \\
\text { working } \\
\text { time } \%\end{array}$ & $\begin{array}{l}\text { Mean time } \\
\text { (minutes) }\end{array}$ & $\underset{\text { Interventions }}{\mathrm{N} .}$ & $\begin{array}{l}\text { Relative } \\
\text { working } \\
\text { time \% }\end{array}$ & $\begin{array}{c}\text { Mean time } \\
\text { (minutes) }\end{array}$ \\
\hline 2300 & Medication Administration & 83 & 4.5 & 6.7 & 616 & 46.5 & 7.2 \\
\hline 2240 & CT Management (CT administration) & 526 & 27.3 & 6.4 & - & - & - \\
\hline 7910 & Consultation & 234 & 20.0 & 10.5 & - & - & - \\
\hline 6480 & Environmental Management & 68 & 3.0 & - & 206 & 11.6 & - \\
\hline 3660 & Wound Care & 9 & 0.9 & 10.3 & - & - & - \\
\hline 7660 & Emergency Cart Checking & 4 & 0.2 & 5.4 & - & - & - \\
\hline 7920 & Documentation & 347 & 16.1 & - & 118 & 7.0 & - \\
\hline 5618 & Teaching: Procedure/Treatment & 57 & 2.8 & 6.0 & 31 & 2.0 & 6.2 \\
\hline 7690 & Laboratory Data Interpretation & 12 & 0.5 & - & - & - & - \\
\hline 4054 & Central Venous Access Device Management & 31 & 2.7 & 10.9 & - & - & - \\
\hline 6680 & Vital Signs Monitoring & 23 & 1.1 & 5.8 & 190 & 12.8 & 6.5 \\
\hline 8140 & Shift Report & 49 & 2.2 & - & 43 & 2.4 & - \\
\hline 7722 & Preceptor: Employee & 38 & 1.7 & - & 10 & 0.6 & - \\
\hline 6574 & Risk Identification (CT prescription analysis) & 33 & 1.6 & 6.1 & - & - & - \\
\hline 7850 & Employee Development & 30 & 1.3 & - & 12 & 0.7 & - \\
\hline 0840 & Positioning & 32 & 1.4 & 5.4 & 27 & 1.5 & 5.4 \\
\hline 7960 & Health Care Information Exchange & 215 & 9.6 & - & 63 & 3.6 & - \\
\hline 6540 & Infection Control & 28 & 1.2 & - & 122 & 6.9 & - \\
\hline \multirow[t]{2}{*}{7160} & Presence & 17 & 0.8 & 5.4 & 12 & 0.7 & 5.4 \\
\hline & Administrative Meeting & 10 & 0.7 & 8.7 & 2 & 0.2 & 8.1 \\
\hline 6574 & Risk Identification (CT double checking) & - & - & - & 25 & 1.4 & - \\
\hline 7680 & Examination Assistance & - & - & - & 2 & 0.1 & 6.3 \\
\hline 4190 & Intravenous (IV) Insertion & - & - & - & 15 & 1.6 & 10.0 \\
\hline 1870 & Tube Care & 1 & 0.1 & 5.8 & 5 & 0.4 & 7.6 \\
\hline 6574 & Risk Identification (patient identification) & 3 & 0.2 & 7.3 & 2 & 0.1 & 5.4 \\
\hline \multirow[t]{2}{*}{8180} & Telephone Consultation & 2 & 0.1 & 8.2 & - & - & - \\
\hline & Total & 1,852 & 100.0 & & 1.501 & 100.0 & \\
\hline
\end{tabular}


Twenty-three interventions were performed by nurses, of which three were recorded: Consultation, Chemotherapy Management (CT administration) and Risk Identification (CT prescription analysis), and accounted for $48.9 \%$ of the relative working time of nurses. Support interventions accounted for $51.1 \%$.

Among the interventions, five were more representative in relation to the relative working time of nurses, namely: CT Management (CT administration); Consultation; Documentation; Health Care Information Exchange and Medication Administration. When added together, they represented $77.5 \%$ of the relative working time.

Regarding nursing technicians, Table 1 shows 18 interventions performed with three recorded: Risk Identification (CT double checking), Medication Administration, Vital
Signs/Anthropometric Monitoring, which corresponded to $58.4 \%$ of relative working time. Support interventions accounted for $41.6 \%$ of relative working time.

Among the 18 interventions, the five with the greatest relative working time of this professional category represented 84.8\%, namely: Medication Administration, Vital Signs/Anthropometric Monitoring, Environmental Control, Documentation and Infection Control.

\section{NURSING DIMENSIONING ACCORDING TO THE WISN}

The mean time values, the annual production of interventions recorded, the percentage of working time spent in support interventions and the identification of TTD allowed to calculate the staff of nurses and nursing technicians processed by electronic spreadsheets (Charts 1 and 2).

Chart 1 - Dimensioning of nurses of the CT outpatient clinic according to the WISN method - São Paulo, SP, Brazil, 2017.

\begin{tabular}{|c|c|c|c|c|c|}
\hline \multicolumn{6}{|c|}{ DIMENSIONING OF NURSING STAFF: ONCOLOGY AMBULATORY } \\
\hline \multirow{2}{*}{ Item } & Origin of parameters & Chemotherapy & Professional: & Nurse & \multirow{2}{*}{$\begin{array}{c}\text { Professional category } \\
\text { nurse }\end{array}$} \\
\hline & \multicolumn{4}{|c|}{ Available Work Time (AWT) } & \\
\hline TTD & \multicolumn{4}{|c|}{ Available work time (hours per year/professional) } & 1688 \\
\hline Item & Recorded interventions & $\begin{array}{l}\text { Annual production of } \\
\text { intervention }(p)\end{array}$ & \multicolumn{2}{|c|}{$\begin{array}{l}\text { Mean time of interventions of the nurse } \\
\text { (T) hours }\end{array}$} & $\begin{array}{c}\text { Required quantity of } \\
\text { nurse } \\
Q(p \times t) / t t d\end{array}$ \\
\hline 1 & Consultation & 54838 & \multicolumn{2}{|c|}{0.17} & 5.52 \\
\hline 2 & $\begin{array}{l}\text { CT management (CT } \\
\text { administration) }\end{array}$ & 90475 & \multicolumn{2}{|c|}{0.10} & 5.36 \\
\hline 3 & $\begin{array}{l}\text { Risk identification (CT } \\
\text { prescription) }\end{array}$ & 31061 & \multicolumn{2}{|c|}{0.10} & 1.84 \\
\hline A & \multicolumn{4}{|c|}{ Total required in category: nurse for service interventions } & 12.72 \\
\hline \multirow[t]{2}{*}{ Item } & \multicolumn{4}{|c|}{ Suport interventions } & $\begin{array}{c}\text { Percentage } \\
\text { participation of nurse }\end{array}$ \\
\hline & \multicolumn{4}{|c|}{$\begin{array}{l}\text { Teaching: Procedure and Treatment / Infection Control / Vital Signs and Antropometrics Monitoring / Medication } \\
\text { Administration / Documentation / Laboratory Data Interpretation / Positioning / Presence / Shift Report / Tube } \\
\text { Care / Wound Care / Administrative Meting / Environmental Management / Health Care Information Exchange } \\
\text { / Central Venous Access Device Management / Risk identification (patient identification) / Emergency Cart } \\
\text { Checking / Telephone Consultation / Preceptor: Employee }\end{array}$} & 49.45 \\
\hline $\mathrm{S} \%$ & \multicolumn{4}{|c|}{ Sum of percentage of category allowance in support services } & 49.45 \\
\hline B & \multicolumn{4}{|c|}{ Category allowance factor: $\{1 /[1(\mathrm{~s} \% / 100)]\}$} & 1.98 \\
\hline $\mathbf{I}$ & \multicolumn{4}{|c|}{ Allowances standard (hours/year) } & \\
\hline 1 & \multicolumn{4}{|c|}{ Interconsulta (Specialty: chemotherapy) } & 2704.00 \\
\hline \multirow[t]{2}{*}{2} & \multicolumn{4}{|c|}{ Teaching: group (Conte com a gente) } & 260.00 \\
\hline & \multicolumn{4}{|c|}{ Sum of hours used in additional interventions } & 2964.00 \\
\hline C & \multicolumn{4}{|c|}{ Individual allowance factor $=\mathrm{I} / \mathrm{AWT}$} & 1.76 \\
\hline $\mathbf{Q}$ & \multicolumn{4}{|c|}{ Total required in a category: Nurse $Q=(A . B)+C$} & 27 \\
\hline
\end{tabular}

Source: Calculation spreadsheet developed by por Bonfim et al., cited by $\operatorname{Cofen}^{(5)}$ and adapted to the study.

Chart 1 shows two additional interventions related to health care projects in this sector. The "Count on Us" (Free translation: Conte com a Gente) project is a collective activity performed by a multiprofessional team (including nurses) for patients and family members attending the $\mathrm{CT}$ outpatient clinic for the first time. The Interconsulta 
contemplates the work of CT outpatient clinic nurses as consultants of the nurse responsible for the patient receiving $\mathrm{CT}$ in the inpatient unit or intensive care unit, and offers guidance on the order of infusion, infusion reaction, prevention and treatment of extravasation, among other aspects.

Chart 2 - Dimensioning of nursing technicians of the CT outpatient clinic according to the WISN method - São Paulo, SP, Brazil, 2017.

\begin{tabular}{|c|c|c|c|c|c|}
\hline \multicolumn{6}{|c|}{ DIMENSIONING OF NURSING STAFF: ONCOLOGY AMBULATORY } \\
\hline \multirow{2}{*}{ Item } & Origin of parameters & Chemotherapy & Professional: & Technician & \multirow{2}{*}{$\begin{array}{l}\text { Professional category } \\
\text { technician }\end{array}$} \\
\hline & \multicolumn{4}{|c|}{ Available Working Time (AWT) } & \\
\hline TTD & \multicolumn{4}{|c|}{ Available working time (hours per year/professional) } & 1576 \\
\hline Item & Recorded interventions & $\begin{array}{l}\text { Annual production of } \\
\text { intervention }(p)\end{array}$ & \multicolumn{2}{|c|}{$\begin{array}{l}\text { Mean time of interventions of the Technician } \\
\text { (T) hours }\end{array}$} & $\begin{array}{l}\text { Required quantity of } \\
\text { technician } \\
Q(p \times t) / t t d\end{array}$ \\
\hline 1 & Medical Administration & 104566 & \multicolumn{2}{|c|}{0.12} & 7.96 \\
\hline 2 & Vital Signs & 103402 & \multicolumn{2}{|c|}{0.10} & 6.56 \\
\hline 4 & $\begin{array}{l}\text { Risk identification } \\
\text { (Double checking CT) }\end{array}$ & 90475 & \multicolumn{2}{|c|}{0.09} & 5.17 \\
\hline A & \multicolumn{4}{|c|}{ Total required in category: Technician for record interventions } & 19.69 \\
\hline \multirow[t]{2}{*}{ Item } & \multicolumn{4}{|l|}{ Suport interventions } & $\begin{array}{l}\text { Percentage participation } \\
\text { of technician }\end{array}$ \\
\hline & \multicolumn{4}{|c|}{$\begin{array}{l}\text { Teaching: Procedure / Treatment / Infection Control / Documentation / Positioning / Presence / Shift Report / } \\
\text { Tube Care / Administrative Meeting / Environmental Control / Health Care Information / Risk Identification } \\
\text { (patient identification) Intravenous Insertion / Preceptor: Employee / Examination Assistance }\end{array}$} & 38.66 \\
\hline $\mathrm{S} \%$ & \multicolumn{4}{|c|}{ Sum of percentage of category allowance in support services } & 38.66 \\
\hline B & \multicolumn{4}{|c|}{ Category allowance factor: $\{1 /[1(\mathrm{~s} \% / 100)]\}$} & 1.63 \\
\hline \multirow[t]{2}{*}{$\mathbf{I}$} & \multicolumn{4}{|c|}{ Allowances standard (hours/year) } & \\
\hline & \multicolumn{4}{|c|}{ Sum of hours used in additional interventions } & 0.00 \\
\hline C & \multicolumn{4}{|c|}{ Individual allowance factor $=\mathrm{A} / \mathrm{AWT}$} & 0.00 \\
\hline $\mathbf{Q}$ & \multicolumn{4}{|c|}{ Total required in a category: technician $Q=(A . B)+C$} & 32 \\
\hline
\end{tabular}

Source: Calculation spreadsheet developed by por Bonfim et al., cited by Cofen ${ }^{(5)}$ and adapted to the study.

\section{ANALYSIS AND INTERPRETATION OF WISN RESULTS}

Table 2 shows the evaluation of the current nursing staff in the framework developed by the WISN method.

Table 2 - Comparison of the number of current nursing professionals with that projected by the WISN method, CT outpatient clinic - São Paulo, SP, Brazil, 2017.

\begin{tabular}{lcccccc}
\hline Category & $\begin{array}{l}\text { ICESP existing WISN } \\
\text { professionals* }\end{array}$ & staff & Difference & $\begin{array}{c}\text { Problem in } \\
\text { workload }\end{array}$ & Ratio Pressure \\
\hline Nurse & 25 & 27 & -2 & Insufficient & 0.9 & Low \\
Technician & 31 & 32 & -1 & Insufficient & 1.0 & Normal \\
\hline
\end{tabular}

*Instituto do Câncer de São Paulo Octavio Frias de Oliveira

\section{DISCUSSION}

At the institution where the study was conducted, the $\mathrm{CT}$ outpatient nursing staff can offer exclusive dedication to the strict quality and safety issues required in $\mathrm{CT}$ infusion. Complementary treatments in case of clinical decompensation, such as administration of blood components, immunostimulators and antibiotics are performed in the day hospital, and dressings and patients' first consultations are performed by the nursing staff of the Integrated Outpatient Clinics of this institution.

In the literature, were found four international studies $^{(10-13)}$ and two national studies ${ }^{(8-9)}$, (one in a public hospital and the other in a private hospital) that addressed workloads in the context of chemotherapeutic treatment. Of all these studies, three presented the mean time of interventions ${ }^{(8-9,11)}$, while three ${ }^{(10,12-13)}$ revealed the time spent by the nursing professional during a patient's session. Only one study analyzed the category of nursing technicians ${ }^{(8)}$. The distribution of relative working time in interventions was identified only in the two national studies $^{(8-9)}$.

In the Consultation intervention, was used a longer working time of nurses (19.6\%), compared to the private hospital $^{(8)}(0.3 \%)$ and the public hospital ${ }^{(9)}(2.2 \%)$. This result may be related to the dynamics of the institution where the study was conducted, which determines the performance of the Nursing Consultation for identifying if the patient has any clinical intercurrence contraindicating chemotherapy. Such dynamics is justified by the high volume of patients that prevents CT administration on the day of the medical 
appointment. For the better organization of care, patients start CT within two days after the medical visit. Importantly, this routine does not change the prescribed interval between CT sessions.

In relation to the mean time of the Consultation, as in the institution, in three other studies ${ }^{(8-9,12)}$ the time was below that suggested by the $\mathrm{NIC}^{(3)}$ (46 to 60 minutes). In the present study, the Consultation (10.5 minutes) was above only of the private hospital ${ }^{(8)}(0.5$ minutes), and in the public hospital ${ }^{(9)}$ (23.1 minutes), the result was similar to that of the study in Australia ${ }^{(12)}$ (20.3 minutes). This result is possibly associated with the fact that the first Consultation of the patient under chemotherapy treatment takes place in the Integrated Clinics of the institution on the day the first cycle of medication is prescribed, when the educational process is initiated and the patient is evaluated for possible nursing and multiprofessional demands.

The intervention Central Venous Access Device Management was not among those with higher percentage of nurses' working time (2.7\%), because in the institution, most patients used peripheral venous access for $\mathrm{CT}$ infusion. The difference is more pronounced in the private hospital ${ }^{(8)}$ (9.2\%) than in the public hospital (5\%). Another possible explanation for the difference is that in the institution, the monthly maintenance of the totally implantable long-term central catheter is performed in the day hospital. The mean time of the intervention in the CT outpatient clinic of the institution was 10.9 minutes, in the private hospital ${ }^{(8)}$ it was 14.7 minutes, in the public hospital ${ }^{(9)}$ it was 5.8 minutes, and in the Australian study ${ }^{(12)}$ it was 12 minutes. In all studies, time was lower than that suggested by the $\mathrm{NIC}^{(3)}$ (31 to 45 minutes).

In the present study, the Risk Identification (CT prescription analysis) intervention was analyzed separately given the large daily volume recorded, which reached about 120 analyzes in the CT outpatient clinic with an average time of 6.1 minutes. This intervention consists in checking if antineoplastic chemotherapeutics and the prescribed doses are in accordance with the institutional protocol.

Regarding the Medication Administration intervention performed by nursing technicians, the relative working time $(46.5 \%)$ in the institution was higher than in the private hospital $^{(8)}(2.1 \%)$. Such a discrepant percentage among the studies may be associated to the fact that this intervention is primarily performed by nurses in the private hospital ${ }^{(8)}$. The mean time of this intervention in this study was 7.2 minutes, whereas in the private hospital ${ }^{(8)}$ it was 0.8 minutes and in the Australian study ${ }^{(12)}$, the estimate of this intervention was 4.5 minutes for nurses. In a study with nurses in Turkey, was found that the preparation stage of the drug was of 3.3 minutes $^{(11)}$. In all mentioned sites, the time was in agreement with that suggested by the $\mathrm{NIC}^{(3)}$ (15 minutes or less).

The CT Management (CT administration) intervention was more frequent in the institution (26.7\%) compared to the private hospital ${ }^{(8)}(7.9 \%)$. In the public hospital ${ }^{(9)}$, this intervention was not identified, and CT administration was possibly included in the Medication Administration (11.1\%) intervention. In the institution, the understanding was different by considering the workload of $\mathrm{CT}$ administration as exclusive of nurses and an impact intervention in an oncology hospital.

Regarding the mean time spent in the CT Management (CT administration) intervention, in ICESP (6.4 minutes), the time was shorter than in the private hospital ${ }^{(8)}(12.6 \mathrm{~min}-$ utes). In the public hospital ${ }^{(9)}$, Medication Administration is considered as CT administration, and the mean time found was of 6.2 minutes, close to that obtained in the present study.

Still regarding CT Management, in $\mathrm{NIC}^{(3)}$ the estimation of 46 to 60 minutes includes patient evaluation, recording, CT administration, among other procedures. In this research, such interventions were measured separately. However, when concentrating interventions Risk Identification/CT prescription analysis (6.1 minutes), Consultation (10.5 minutes), Central Venous Access Device Management (10.9 minutes), Medication Administration, which is about two medications per patient (14.4 minutes), two measurements of Vital Signs Monitoring (11.6 minutes), Environmental Control (5.4 minutes), Risk Identification/ CT double checking of two infusion bags (10.8 minutes) and CT Control/CT administration, which is about two infusion bags per patient (12.8 minutes), the sum of interventions that integrate CT Management would be 82.5 minutes per patient in ICESP, which is longer than the time suggested time by $\mathrm{NIC}^{(3)}$.

In a study in a private Brazilian hospital, were found 198.6 minutes (3.3 hours) of nursing care per patient. However, during this time, a single patient can receive all interventions (nurses and nursing technicians) performed in the sector, such as CT Management, Blood Components Administration, Pain Control, Emotional Support, Telephone Follow-up, among others ${ }^{(8)}$.

An Australian study of 36 oncology nurses estimated the mean nursing time of 23 minutes for a patient receiving a $\mathrm{CT}$ infusion bag and a pre-chemotherapy drug. This time included venous access, preparation of CT, infusion of CT and pre-chemotherapy drug, and removal of access, but did not include Consultation (20.3 minutes) or Vital Signs/ Anthropometric Monitoring ${ }^{(12)}$.

A study conducted in Turkey established the mean nursing time according to the patient classification system specific to CT outpatient clinics based on infusion time of the following protocol: level I (up to 15 minutes of treatment with intramuscular or subcutaneous administrations) requires 5.6 minutes of nursing; level VI (more than 240 minutes of treatment with complex CT infusion), 304.4 minutes of nursing ${ }^{(11)}$.

A North American study also proposed a patient classification system, but with other parameters: level I requires 20 minutes of nursing and includes treatments with less time than 30 minutes, such as administration of hormone therapy by intramuscular or subcutaneous routes; level $\mathrm{V}$ requires 180 minutes of nursing for regimen with more than 4 hours (first infusion of paclitaxel, rituximab, ifosfamide or mesna) ${ }^{(10)}$. 
Another American study also proposed a patient classification system, in which the CT administration of 61-120 minutes corresponds to 90 minutes of nursing. In the cases of multiple CT agents associated with pre-medications and hydration, totaling 121-240 minutes of infusion time, the established nursing time was 180 minutes, among other times ${ }^{(13)}$.

These studies showed that depending on the therapeutic regimen administered, the nursing time may be higher than that suggested by the $\mathrm{NIC}^{(3)}$.

For application of the WISN, were identified three recorded interventions, namely Consultation, CT Management (CT administration) and Risk Identification (CT prescription analysis) that corresponded together to $48.9 \%$ of the relative working time. Support interventions accounted for $51.1 \%$ of the relative working time. In the study performed at the Family Health Unit (FHU), was found that four recorded interventions accounted for $38.3 \%$. The 23 support interventions corresponded to $61.7 \%{ }^{(16)}$.

The three interventions registered (Risk Identification/ CT double checking, Medication Administration and Vital Signs/Anthropometric Monitoring) accounted for $22.2 \%$ of the total of 18 interventions performed by nursing technicians in this sector, but they corresponded to $58.4 \%$ of the relative working time.

In the study performed in the FHU, were recorded ten interventions/activities by nursing technicians/assistants that corresponded to $45.2 \%{ }^{(16)}$.

Regarding AWT results, the nurse category presented 1,688 hours, which is in line with data from a study conducted with FHU nurses ${ }^{(16)}$ (1,672 hours) and a study conducted with physicians at a clinic serving HIV patients in western Kenya (1,648 hours) ${ }^{(19)}$, both with a weekly workload of 40 hours, as in the CT outpatient clinic.

In the nursing technician category, the CT Ambulatory obtained AWT of 1,576 hours, which is lower than that found in nursing assistants working at the FHU (1,672 hours $)^{(16)}$. This result is possibly related to the extended medical leave.

Regarding the number of existing and planned nursing professionals dimensioned with use of the WISN method, the differences found were a result of the low workload pressure on nurses and normal pressure on nursing technicians in the studied sector. Most interventions/activities performed by the nursing team of the institution were aprehended by the work sampling method and by operationalization of the steps recommended by the method. The low/normal workload pressure on the categories shows that its distribution between the two is adequate. A study performed at the FHU showed high pressure for nurses and no pressure for nursing technicians ${ }^{(16)}$.

With regard to nursing professionals and patients ratio, in a study conducted in Turkey, was applied the patient classification system called Magnuson Model in a CT outpatient clinic of a university hospital, and the suggestion was allocating 17.1 nurses/day to attend 69 patients/ day, that is, the ratio of 1 nurse to 4 patients ${ }^{(13)}$.

A North American study reported the ratio of 1 nurse to 6-8 patients receiving CT. However, as they understood the workload distribution among nurses was not balanced, a patient classification system was implemented, in which was considered the number of chemotherapy bags to be infused, the need for vesicant drugs in prescriptions, and the presence of comorbidities in the patient ${ }^{(20)}$.

Considering AWT values (vacations, days off, work leaves, among others), in ICESP, out of the 59 dimensioned nursing professionals, 46 would be working daily for the care of 230 patients, which is a ratio of 1 professional to 5 patients.

The dynamic nursing performance was the result of concomitant interventions, for example, Documentation referring to a patient and Health Care Information Exchange related to another patient.

The work sampling method at five-minute intervals does not enable the evaluation of individual practice and the quality of care provided, nor the identification of the proportion of time spent when more than one intervention is performed at the same time.

As one of the researchers had an indirect managerial position in the $\mathrm{CT}$ outpatient clinic, data collection was performed by two observers who were not part of the professional staff of the sector in order to minimize the possible influence on the behavior of participants observed.

\section{CONCLUSION}

The WISN method proved to be applicable to the CT outpatient clinic. The similarity between the staff proposed by the WISN and the current staff showed that most interventions/activities conducted by the nursing team of the institution were apprehended through the work sampling method and by operationalization of the steps recommended in the WISN method.

Considering that the work sampling method is not easily applied in the daily routine of a care sector, the strength of this study lies in the patterns of mean time and relative working time spent by the nursing team that may serve as relevant references for the planning of professionals in other CT outpatient clinics.

The intuitive judgment applied in the use of the Functional Site for dimensioning the nursing professional staff in outpatient units as recommended by Cofen Resolution number 543/2017 can be replaced by data obtained from the analyzed realities and application of the WISN method. Undoubtedly, these contribute to the argumentation of the need for professionals in deliberative organs of health institutions.

Objetivo: Aplicar o método elaborado pela Organização Mundial da Saúde, denominado Workload Indicators of Staffing Need, para dimensionar a equipe de enfermagem para o cuidado de pacientes oncológicos em Ambulatório de Quimioterapia. Método: Trata-se 
de uma pesquisa de campo observacional e documental, com abordagem quantitativa e amostra intencional. Os dados prospectivos foram coletados por meio da técnica amostragem do trabalho. Resultados: Participaram da pesquisa 17 enfermeiros e 12 técnicos de enfermagem. Foram realizadas 3.727 observações, sendo obtidos tempos médios e ocupação relativa de 23 intervenções de enfermeiros e 18 intervenções de técnicos de enfermagem. As intervenções corresponderam a 88,5\% da ocupação relativa dos enfermeiros e 83,9\% dos técnicos de enfermagem. A atividade pessoal foi responsável por $8,2 \%$ da ocupação relativa dos enfermeiros e 7,9\% dos técnicos de enfermagem. O teste de confiabilidade resultou em 86,3\% de concordância. Conclusão: A semelhança entre o quadro projetado pelo método estudado e o existente evidenciou que o Workload Indicators of Staffing Need tem grande potencial e aplicabilidade para dimensionar os profissionais de enfermagem com segurança.

\section{DESCRITORES}

Enfermagem Oncológica; Recursos Humanos de Enfermagem; Carga de Trabalho. Assistência Ambulatorial.

\section{RESUMEN}

Objetivo: Aplicar el método elaborado por la Organización Mundial de la Salud, denominado Workload Indicators of Staffing Need, a fin de dimensionar al equipo de enfermería para el cuidado a pacientes oncológicos en Ambulatorio de Quimioterapia. Método: Se trata de una investigación de campo observacional y documental, con abordaje cuantitativo y muestra intencional. Los datos prospectivos fueron recogidos mediante la técnica de muestreo del trabajo. Resultados: Participaron en la investigación 17 enfermeros y 12 técnicos de enfermería. Fueron realizadas 3.727 observaciones, obteniéndose tiempos medios y ocupación relativa de 23 intervenciones de enfermeros y 18 intervenciones de técnicos de enfermería. Las intervenciones correspondieron al 88,5\% de la ocupación relativa de los enfermeros y el 83,9\% de los técnicos de enfermería. La actividad personal fue responsable del 8,2\% de la ocupación relativa de los enfermeros y el 7,9\% de los técnicos de enfermería. La prueba de confiabilidad resultó en el 86,3\% de concordancia. Conclusión: La semejanza entre el cuadro proyectado por el método estudiado y el existente evidenció que el Workload Indicators of Staffing Need tiene gran potencial y aplicabilidad para dimensionar a los profesionales enfermeros con seguridad.

\section{DESCRIPTORES}

Enfermería Oncológica; Personal de Enfermería; Carga de Trabajo; Atención Ambulatoria.

\section{REFERENCES}

1. Baia WMR, Santos DV. Assistência de enfermagem em oncologia clínica. In: Hoff PMG, organizador. Tratado de oncologia. São Paulo: Atheneu; 2013. p. 1375-85.

2. Brant J, Wickham R. Statement on the scope and standards of oncology nursing practice: generalist and advanced practice. Pittsburgh: Oncology Nursing Society; 2013.

3. Bulechek GM, Butcher HK, Dochterman JM, Wagner CM. NIC Classificações das Intervenções de Enfermagem. $6^{\mathrm{a}}$ ed. Rio de Janeiro: Elsevier; 2016.

4. Fugulin FMT, Gaidzinski RR, Lima AFC. Dimensionamento de pessoal de enfermagem em instituições de saúde. In: Kurcgant $P$, coordenadora. Gerenciamento em enfermagem. $3^{\mathrm{a} e d . ~ R i o ~ d e ~ J a n e i r o: ~ G u a n a b a r a ~ K o o g a n . ~ 2016 ; ~ p . ~ 115-27 . ~}$

5. Conselho Federal de Enfermagem. Resolução Cofen n. 543/2017. Atualiza e estabelece parâmetros para o Dimensionamento do Quadro de Profissionais de Enfermagem nos serviços/locais em que são realizadas as atividades de enfermagem [Internet]. Brasília; 2017 [citado 2017 out. 10]. Disponível em http://www.cofen.gov.br/wp-content/uploads/2017/05/RESOLU\%C3\%87\%C3\%83O-COFEN-N\%C2\%BA543-2017-completa.pdf

6. World Health Organization. Workload Indicators of Staffing Need (WISN). User's manual [Internet]. Geneva: WHO; 2010 [cited 2014 Sep 01]. Available from: http://www.who.int/hrh/resources/WISN_Eng_UsersManual.pdf?ua=1

7. McQuide PA, Aitken Kolehmainen R, Forster N. Applying the workload indicators of staffing need (WINS) method in Namibia: challenges and implications for human resources for health. Hum Resour Health. 2013;11:64.

8. Martin LGR, Gaidzinski RR. Creating and validating an instrument to identify the workload at na oncology and hematology outpatient service. Einstein. 2014;12(3):323-9.

9. Souza CA, Jericó MC, Perroca MG. Measurement of nurses' workload in an oncology outpatien clinic. Rev Esc Enferm USP 2014;48(1):97103. DOI: http://dx.doi.org/10.1590/ S0080-623420140000100012

10. DeLisle J. Designing an acuity tool for ambulatory oncology setting. Clin J Oncol Nurs. 2009;13(1):45-50.

11. Tuna R, Bayakal U, Turkmen E, Yildirim A. Planning for the size of the nursing staff at outpatient chemotherapy unit. Clin J Oncol Nurs. 2015;19(6):115-20.

12. Raad J, Gool K, Haas M, Haywood P, Faedo M, Gallego G, et al. Nursing takes time: workload associated with administering cancer protocols. Clin J Oncol Nurs. 2010;14(6):735-41.

13. Moore M, Hastings C. The evolution of ambulatory nursing intensity sistem. JONA. 2006. 36(5):241-8.

14. Bonfim D, Fugulin FMT, Laus AM, Peduzzi M, Gaidzinski RR. Time standards of nursing in the Family Health Strategy: an observational study. Rev Esc Enferm USP. 2016;50(1):118-26.

15. Pierantoni C, Varella T, Santos M, Silva L. Indicadores de carga de trabalho para profissionais da Estratégia de Saúde da Família. In: Pierantoni C, Dal Poz MR, França T, organizadoras. O trabalho em saúde: abordagens quantitativas e qualitativas. Rio de Janeiro: CEPESC:IMS/UERJ; 2011. p. 120-48.

16. Bonfim D, Laus AM, Leal AE, Fugulin FMT, Gaidzinski RR. Application of the Workload Indicators of Staffing Need method to predict nursing human resources at Family Health Service. Rev Latino Am Enfermagem [Internet]. 2016 [cited 2017 out. 10];24:e2683. Available from: http://www.scielo.br/pdf/rlae/v24/pt_0104-1169-rlae-24-02683.pdf 
17. Finkler AS, Knickman JR, Hendrickson G, Lipkin Jr M, Thompson LUG. A comparison of Work-Sampling and Time-and-Motion Techniques for Studies in Health Services Research. HSR: Health Service Research, December 1993. 28(5): 577-97.

18. Brasil. Ministério da Saúde; Conselho Nacional de Saúde. Resolução n. 466, de 12 de dezembro de 2012. Dispõe sobre diretrizes e normas regulamentadoras de pesquisas envolvendo seres humanos [Internet]. Brasília; 2012 [citado 2017 nov. 28]. Disponível em http://conselho. saude.gov.br/resolucoes/2012/reso466.pdf19

19. Burmen B, Owuor N, Mitei P. An assessment of staffing needs at a HIV clinic in a Western Kenya using the WHO workload indicators of staffing need WISN, 2011. Hum Resour Health. 2017;15:9. DOI: https://doi.org/10.1186/s12960-017-0186-3

20. Votherns J, Spoden B, Wilcken J. From evidence to practice: developing out patient acuity: based staffing model. Clin J Oncol Nurs. 2015;19(3):332-7. 